Religare, ISSN: 19826605, v.16, n.1, agosto de 2019, p.140-169.

\title{
Uma batalha pelas mentes: Tim LaHaye e a ascensão da Direita Cristã norte-americana
}

\author{
A battle for the minds: Tim LaHaye and the rise of the \\ Christian Right in America
}

Daniel Rocha ${ }^{1}$

\section{Resumo}

Este artigo analisa a participação do pastor batista Tim LaHaye na mobilização política que caracterizou importantes setores do fundamentalismo protestante norte-americano nas décadas de 1970 e 1980. Além das ações efetivas de LaHaye no campo da política juntamente com Jerry Falwell e outras lideranças da Maioria Moral, examinaremos mais detalhadamente suas perspectivas sobre como deveria se dar a atuação dos cristãos norte-americanos na arena política. Para tal, faremos um exame detalhado de seu livro The Battle For The Mind (1980), obra que se tornou uma referência importante na construção do discurso da Direita Cristã norte-americana. Inicialmente, apresentaremos um breve histórico da atuação política de Tim LaHaye ao longo da década de 1970 nos Estados Unidos. Na sequência, analisaremos as questões e argumentos principais da obra The Battle For The Mind de LaHaye. Por fim, faremos uma breve reflexão, baseada ainda no livro de LaHaye, sobre como a crença na iminência do fim dos tempos (crença pela qual LaHaye se tornou mais conhecido) se compatibilizou com um projeto de "re-cristianização" da sociedade norte-americana.

Palavras-chave: Fundamentalismo; História dos Estados Unidos; Religião e política; Direita cristã.

\section{Abstract}

This article analyzes the participation of Baptist pastor Tim LaHaye in the political mobilization that characterized important sectors of American Protestant fundamentalism in the 1970s and 1980s. In addition to the effective actions of LaHaye in the field of politics together with Jerry Falwell and other leaders of the Moral Majority, we will examine in more detail their perspectives on how American Christians should act in the political arena. To do so, we will take a detailed look at his book The Battle For The Mind (1980), a book that has become an important reference in the construction of the Christian Right's

\footnotetext{
${ }^{1}$ Bolsista do Programa Nacional de Pós-Doutorado (PNPD) da CAPES e Professor Colaborador no Programa de Pós-Graduação em Ciências da Religião da Pontifícia Universidade Católica de Minas Gerais (PUC Minas). Doutor em História pela Universidade Federal de Minas Gerais (UFMG). E-mail: danielrochabh@yahoo.com.br
} 
Religare, ISSN: 19826605, v.16, n.1, agosto de 2019, p.140-169.

discourse. Initially, we will present a brief history of Tim LaHaye's political activities throughout the 1970s in the United States. Then, in the sequel, we will discuss the main issues and arguments that come from LaHaye's The Battle For The Mind. Finally, we will make a brief reflection, based on LaHaye's book, on how the belief in the imminence of the end of the world (belief by which LaHaye became better known) was compatible with a project of "re-Christianization" of the American society.

Keywords: Fundamentalism; History of the United States; Religion and politics; Christian right.

\section{Introdução}

Campo Grande, 26 de agosto de 2013. O conhecido pastor pentecostal brasileiro Silas Malafaia, num evento chamado "Marcha para Jesus", fez a seguinte declaração em seu discurso para uma multidão de aproximadamente 40.000 pessoas: “Nós declaramos que vamos tomar posse dos meios de comunicação, das redes de internet, do processo político. Nós vamos fazer a diferença, vamos influenciar o Brasil com o evangelho de Jesus"².

Câmara dos Deputados, Brasília, 05 de junho de 2013. O deputado evangélico Arolde de Oliveira do PSD/RJ afirma durante um discurso feito no plenário daquela casa legislativa: "Somos um país cristão, um país ocidental, um país judaico-cristão, sim, e rejeitamos as filosofias e os princípios desse humanismo ateu que quer ser implantado no Brasil, auxiliado por ideologias que já ficaram no passado e que já causaram tantos danos a gerações e gerações"33.

As duas citações acima exemplificam algumas ênfases dos discursos e perspectivas políticas de lideranças religiosas fundamentalistas e de políticos evangélicos no Brasil. Posicionamentos como o de Malafaia e Arolde de Oliveira vêm surpreendendo aqueles que imaginavam um século XXI no qual a religião

\footnotetext{
${ }^{2} \mathrm{O}$ trecho do discurso de Malafaia foi retirado da reportagem "Marcha para Jesus reúne 40 mil e Malafaia dispara contra os gays" do site Campo Grande News. Disponível em: https://www.campograndenews.com.br/cidades/capital/marcha-para-jesus-reune-40-mil-emalafaia-dispara-contra-gays. Acesso em: 25 fev. 2018.

3 Os discursos e notas taquigráficas das últimas legislaturas da Câmara dos Deputados encontram-se disponíveis no site: http://www2.camara.leg.br/deputados/discursos-e-notastaquigraficas. Acesso em: 10 set. 2018.
} 
Religare, ISSN: 19826605, v.16, n.1, agosto de 2019, p.140-169.

estaria totalmente ausente da ordem do dia. $\mathrm{O}$ "evangelho de Jesus" não deveria ter lugar na arena política, território não mais dos deuses, mas dos homens. Nos setores mais liberais da sociedade, estamos acostumados a ler e ouvir sobre o perigo que os fundamentalistas religiosos representariam ao Estado laico e às liberdades individuais. De outro lado, nos púlpitos das igrejas e nos discursos dos políticos e lideranças religiosas, ouvimos falar de outro tipo de ameaça: a de uma política e de um judiciário que teriam virado as costas para os valores divinamente inspirados e que deveriam ordenar a vida social. A desagregação das famílias, a corrupção moral, a violência, o uso de drogas etc. seriam consequências desse movimento de afastamento dos valores cristãos na criação e aplicação das leis. Para os pesquisadores do processo de politização do fundamentalismo protestante norte-americano, que ganhou força no final dos anos 1970, a sensação de déjà vu é inescapável.

Neste artigo, analisaremos o importante papel desempenhado pelo pastor batista Tim LaHaye na ascensão do conservadorismo protestante "politicamente engajado" no final da década de 1970 e início dos anos 1980 nos Estados Unidos. Segundo Urban (2006), nas últimas décadas do século XX, Tim LaHaye surgiu não apenas como o teólogo responsável pela disseminação das crenças dispensacionalistas ${ }^{4}$ em relação ao fim dos tempos, mas, também, como uma das figuras mais influentes da Direita Cristã norte-americana. Quando o Institute For The Study Of American Evangelicals (Instituto para o Estudos dos Evangélicos Norte-Americanos) decidiu eleger o mais influente líder evangélico dos últimos 25 anos, eles não escolheram Billy Graham, Pat Robertson ou Jerry Falwell, mas sim Tim LaHaye, em grande parte por causa de sua participação na política norte-americana. Em uma reportagem sobre o falecimento de LaHaye, a revista Time dizia que o velho pastor de 90 anos havia sido um dos grandes pilares da

\footnotetext{
${ }_{4}^{4}$ Perspectiva escatológica pré-milenarista (o reinado milenar de Cristo na Terra ocorrerá somente após o seu retorno), na qual o plano de Deus relativo à salvação do homem deveria ser compreendido a partir de uma divisão em dispensações ou sete períodos atestados biblicamente, sendo o último período o reinado milenar de Cristo na Terra.
} 
Religare, ISSN: 19826605, v.16, n.1, agosto de 2019, p.140-169.

politização das lideranças fundamentalistas no final da década de 1970 e na fundação da Moral Majority (Maioria Moral), inclusive citando o fato de que Jerry “Falwell foi inspirado a dar início ao grupo em 1979 após ver como LaHaye havia organizado vários colegas pastores para trabalharem a favor de causas conservadoras na Califórnia durante a década de 1970”5.

Além disso, especialmente através de seu livro The Battle For The Mind (A batalha pela mente) de 1980, LaHaye tornou-se um dos principais articuladores do discurso do conservadorismo religioso norte-americano. O objetivo do presente texto, a partir de uma perspectiva histórica, é apresentar a importância do papel de Tim LaHaye na Direita Cristã norte-americana, tanto nas suas ações práticas, como organização de lobbies e grupos organizados de atuação política, quanto na construção de um discurso articulado que inspirou várias pautas do conservadorismo religioso norte-americano e que continua a reverberar naquele país e em outros onde o modus operandi da Direita Cristã norte-americana exerceu (e continua exercendo) influência.

$\mathrm{Na}$ primeira seção do presente artigo, enfatizando a dimensão prática/pragmática de sua atuação política, traçaremos um breve histórico da atuação política de Tim LaHaye, inicialmente em San Diego e na Califórnia e, no final da década de 1970, na organização da Maioria Moral, na qual, juntamente com Jerry Falwell, tornou-se um dos grandes referenciais para a mobilização política dos grupos fundamentalistas nos Estados Unidos. Procuramos demonstrar a importância de se compreender a "politização" do discurso de LaHaye dentro do contexto de uma crescente "onda conservadora" na política norte-americana da década de 1970. Na sequência, analisaremos as questões e argumentos principais da obra The Battle For The Mind de LaHaye, um livro que se tornou uma referência importante na construção do discurso da Direita Cristã

\footnotetext{
${ }^{5}$ No original: "Falwell was inspired to start the group in 1979 after seeing how LaHaye had organized scores of fellow pastors to work for conservative political causes in California in the '70s".

Disponível

em: http://content.time.com/time/specials/packages/article/0,28804,1993235_1993243_1993291,00.htm 1. Acesso em: 17 jun. 2018.
} 
Religare, ISSN: 19826605, v.16, n.1, agosto de 2019, p.140-169.

norte-americana engajada numa culture war (guerra cultural) contra o que chamavam de humanismo secular. Por fim, ainda a respeito da influência de The Battle For The Mind, examinaremos como a crença na iminência do fim dos tempos (crença pela qual LaHaye se tornou mais conhecido) pôde se compatibilizar com um projeto de "resgatar" os "valores cristãos" na sociedade norte-americana e construir um futuro melhor para seus "filhos e netos".

\section{LaHaye e a Maioria Moral}

Tim LaHaye faleceu no dia 25 de julho de 2016, aos 90 anos de idade. Importante personagem do fundamentalismo protestante norte-americano das três últimas décadas do século XX, LaHaye tornou-se mundialmente conhecido - especialmente nos meios evangélicos (mas não só) - por ter sido um dos autores da série de ficção apocalíptica Left Behind, escrita em coautoria com Jerry Jenkins. A série é composta de 16 livros que foram lançados entre 1995 e 2007. A história é, basicamente, uma interpretação literalista do livro do Apocalipse dentro do contexto geopolítico das décadas de 1990 e 2000. O arrebatamento prétribulacional dos crentes ocorre, o Anticristo controla a ONU e cria um sistema econômico global integrado. Enquanto isso, um pequeno grupo de cristãos norteamericanos, que, devido à sua falta de fé, foi "deixado para trás" no advento do Arrebatamento ${ }^{6}$, combate as forças do mal, aguardando o desfecho final. Essa série de livros já havia vendido até 2004 mais de 62 milhões de cópias (MARSDEN, 2006, p. 249). Tal "aventura apocalíptica" ganhou também versões cinematográficas de relativo sucesso e acabou até nas telas dos videogames. LaHaye também escreveu vários livros de sucesso sobre diferentes áreas da vida

\footnotetext{
${ }^{6} \mathrm{O}$ Arrebatamento (rapture) dos crentes é a crença de que os "verdadeiros cristãos" que vivessem nos últimos dias seriam assuntos aos céus, sem passar pela experiência da morte. Embora haja variantes sobre como tal fato ocorreria, LaHaye acreditava em um arrebatamento prétribulacional, que ocorreria antes da Tribulação que marcaria o reinado do Anticristo na Terra e os grandes conflitos do final dos tempos. Os "arrebatados" retornariam à Terra junto com Cristo após tais acontecimentos para reinar com Ele durante os mil anos e, após esse período, viver eternamente na Jerusalém celestial.
} 
Religare, ISSN: 19826605, v.16, n.1, agosto de 2019, p.140-169.

cristã, especialmente sobre o combate à depressão, o controle do temperamento e, inclusive, sobre preceitos para uma vida sexual sadia para os casais cristãos. Junto com sua esposa Beverly, LaHaye escreveu The Act of Marriage: The Beauty of Sexual Love que, de acordo com Timothy Weber (2004, p. 192), vendeu mais de 2,5 milhões de cópias.

Em meados da década de 1970, LaHaye era pastor de uma enorme igreja batista - Scott Memorial Baptist Church - em San Diego, possuía um programa de televisão em rede nacional e, como dissemos, já era autor de livros de grande circulação no meio evangélico. Ele também havia se tornado um dos principais articuladores do movimento em torno da criação de escolas cristãs. Na Califórnia, ele foi responsável pela implantação de doze escolas cristãs, entre elas o Christian Heritage College e, também, o Institute for Creation Research (Instituto para Pesquisas sobre a Criação), que procurava difundir o "criacionismo científico".

Apesar da grande base de apoio aos fundamentalistas estar na região chamada de Bible Belt (Cinturão da Bíblia)" é importante salientar que a influência das principais lideranças protestantes conservadoras da década de 1970 se estendia também por outras regiões do país. Tim LaHaye concentrava seu ministério na área do chamado Sun Belt (Cinturão do Sol) norte-americano, região que acolheu com grande fervor a mensagem do novo conservadorismo religioso. De acordo com Alves Jr. (2013), o sul da Califórnia recebeu, durante as décadas de 1930 e 1940, grandes levas de imigrantes sulistas em busca de trabalho. Após experiências pastoreando igrejas na área rural da Carolina do Sul e em Minneapolis, LaHaye chegou a San Diego em 1956 e - apesar de conviver com liberalismo nos costumes que marcou as grandes cidades da Califórnia durante a década de 1960 - conseguiu uma grande base de apoio de fiéis com sua

\footnotetext{
7 Área do território norte-americano onde a religiosidade protestante tradicional ainda possui muita força. Concentra-se na região sudeste dos Estados Unidos, abrangendo estados inteiros como Alabama, Georgia, Mississipi, Arkansas etc., e partes de outros, como o norte da Flórida, o sul de Ohio e Illinois etc.
} 
Religare, ISSN: 19826605, v.16, n.1, agosto de 2019, p.140-169.

formação religiosa e moral muito ligada à tradição religiosamente conservadora do sul do país.

Antes da fundação da Maioria Moral, LaHaye já havia feito algumas “incursões" no campo político. Apesar de, segundo Williams (2010, p. 73), ter se interessado muito pouco por questões políticas antes de sua chegada a San Diego, a partir de meados da década de 1960 "LaHaye passou a se envolver no emergente movimento conservador que estava profundamente desconfiado do comunismo, dos gastos com políticas de bem-estar social e da permissividade cultural e que via Barry Goldwater como um herói"8. Antes das primárias do Partido Republicano na Califórnia para a escolha do candidato à presidência nas eleições de 1964, LaHaye tentou mobilizar alguns pastores para que apoiassem Goldwater, que concorria contra o liberal e "moralmente condenável" governador de Nova York Nelson Rockefeller.

Em 1966, LaHaye foi um dos fundadores da CLEAN - California League Enlisting Action Now (Liga de Alistamento da Califórnia para Ação Imediata), uma organização que buscava combater a produção e a distribuição de material pornográfico no estado. Apesar do pouco sucesso da CLEAN, ela ganhou o apoio do conservador pré-candidato republicano ao governo do estado: o ex-ator Ronald Reagan. LaHaye manteve uma boa relação com Reagan e exaltava os feitos de sua administração na Califórnia. Em 1980, às vésperas da eleição que levaria ex-ator à Casa Branca, LaHaye (1980, p. 155) dizia que "Ronald Reagan foi governador do maior estado da União por oito anos, 1967 a 1974, onde ele reduziu o tamanho do governo, dos programas de bem-estar social e do desperdício, deixando o estado com mais de 500 milhões de dólares em caixa"9.

\footnotetext{
${ }^{8}$ No original: "LaHaye became involved in an emerging conservative movement that was deeply suspicious of communism, social welfare spending, and cultural permissiveness, and that viewed Barry Goldwater as a hero".

${ }^{9}$ No original: "Ronald Reagan had been the governor of the largest state in the union for eight years, 1967-1974, where he reduced the size of government, welfare, and waste, leaving the state with over 500 million dollars in its treasury".
} 
Religare, ISSN: 19826605, v.16, n.1, agosto de 2019, p.140-169.

Se Reagan era visto com enorme simpatia por LaHaye, o mesmo não se pode dizer de seu oponente nas eleições de 1980: o à época ainda presidente Jimmy Carter. LaHaye acusava Carter de ser um cristão omisso e aliado dos inimigos do Evangelho e da "boa moral". Carter teria traído o voto de milhões de born again christians (cristãos renascidos) que criam que o presidente "renascido" seria uma importante ferramenta para "re-cristianizar" a cultura norte-americana. Ao invés disso, ele teria se unido a liberais, feministas, homossexuais etc. e aberto a estrutura governamental norte-americana para o usufruto de grupos humanistas e "anticristãos". LaHaye visitou Carter junto com uma delegação de pastores fundamentalistas - entre eles Jerry Falwell - com o objetivo de pressionar o presidente para que este se posicionasse contra a legalização do aborto entre outros temas. As respostas de Carter não agradaram ao grupo e, de acordo com Morone (2003, p. 453), quando "Tim LaHaye deixou o gabinete do presidente, ele inclinou sua cabeça e orou: 'Deus, precisamos tirar esse homem da Casa Branca e colocar aqui alguém que seja incisivo na busca pela restauração dos valores morais tradicionais ${ }^{\prime \prime 10}$.Em 1980, LaHaye escreveu:

Pessoalmente, eu prefiro eleger um homem comprometido com a moralidade bíblica do que um que diz em alta voz que é um cristão renascido, mas se recusa a deixar clara sua posição moral. Por exemplo, nós temos acompanhado a presidência de um líder que se proclama cristão renascido, mas que se cercou de assessores imorais ou amorais durante sua campanha. Após sua eleição, ele nomeou a maioria dessas pessoas para compor seu gabinete, juntamente com uma longa relação de humanistas, que o representam na administração de seu governo. Pelo que sabemos, ele não nomeou nenhum cristão renascido, ou mesmo um pro-moralista mais agressivo para nenhum cargo importante. Os homens podem ser melhor julgados por suas companhias e pelos conselheiros que escolhem do que por declarações de fé politicamente motivadas (LAHAYE, 1980, p. 232) $)^{11}$.

\footnotetext{
${ }^{10}$ No original: "as the Reverend Tim LaHaye left the president's office he bowed his head and prayed: 'God, we have got to get this man out of the White House and get someone in here who will be aggressive about bringing back traditional moral values'".

${ }^{11}$ No original: "Personally, I would rather elect a man commited to biblical morality than one who loudly proclaims that he is a born-again Christian but refuses to define his moral position.
} 
Religare, ISSN: 19826605, v.16, n.1, agosto de 2019, p.140-169.

No final do governo Carter, por volta de 1979, várias lideranças protestantes fundamentalistas norte-americanas passaram a advogar a ideia de que os verdadeiros crentes no Senhor Jesus Cristo não poderiam mais assistir de braços cruzados a decadência da nation under God (nação sob Deus), que estaria sendo fomentada pela geração dos anos sessenta e por governos ímpios. A "América" deveria voltar para os trilhos de seu caminho rumo ao futuro luminoso. Cientes disso e colocando a herança cristã como a principal base sobre a qual essa nação-exemplo teria sido construída, tais lideranças buscaram direcionar seu discurso ao que chamavam de "maioria silenciosa". Entendiam que a grande maioria dos norte-americanos também via com desconforto os rumos políticos e morais do país. Entretanto, essa maioria estaria desmobilizada: apenas lamentava o fato e não agia politicamente para tentar reverter a situação. Com o intuito de criar um instrumento para transformar o descontentamento em prática política, foi organizada a Moral Majority (Maioria Moral), “cuja função seria a de registrar novos eleitores, informar e mobilizar as pessoas, levando-as para o debate político com suas principais bandeiras em defesa da vida, da moral, da pátria e do Estado de Israel, influenciando assim as eleições, e principalmente o Partido Republicano" (FINGUERUT, 2009, p. 122). Jerry Falwell se tornou o porta-voz da organização ${ }^{12}$ e Robert J. Billings o seu secretário-executivo e um dos principais responsáveis pela organização de lobbies fundamentalistas em Washington.

For example, we have witnessed the presidency of a self-acknowledged, born-again leader who surrounded himself with amoral or immoral promoters during his campaign. When elected, he appointed most of these same people to office, together with a long list of humanists, who represent him in the administration of his government. As far as we know, he did not appoint one born-again Christian, or even an aggressive pro-moralist, to any major office. Men can be judged better by the company they keep and the kind of advisors they select than by their politically motivated statements of faith".

${ }^{12}$ Sobre a militância política e religiosa de Jerry Falwell ver: HARDING, Susan Friend. The book of Jerry Falwell. Princeton: Princeton University Press, 2000; WINTERS, Maichael Sean. God's Right Hand: How Jerry Falwell Made God a Republican and Baptized the American Right. New York: Harper One, 2012. 
Religare, ISSN: 19826605, v.16, n.1, agosto de 2019, p.140-169.

Rapidamente a Christian Right (Direita Cristã) ${ }^{13}$ da qual a Maioria Moral seria a principal organização, se tornou uma grande força política nos Estados Unidos e tinha como principais bandeiras: a defesa dos "valores da família" (o que incluía a oposição ao aborto em qualquer caso, o combate à expansão dos direitos dos homossexuais e, também, a restrição à pornografia); a volta da prática das orações e o ensino do criacionismo nas escolas públicas; o combate à disseminação do comunismo, juntamente com uma ferrenha defesa de cunho patriótico do capitalismo e do "modo de vida" americano; uma posição extremamente crítica às políticas de bem-estar social; a defesa de uma postura Pró-Israel por parte do governo norte-americano, entre outras.

Esse movimento acabaria se tornando uma importante base popular para o conservadorismo e para o Partido Republicano que, com as seguidas decepções dos fundamentalistas com os governos democratas, acabou recebendo a simpatia e tornando-se o abrigo partidário das lideranças da Direita Cristã. Com sua força crescente, a Maioria Moral se mobilizava no sentido de cadastrar eleitores, apoiar candidatos que abraçassem suas bandeiras e trabalhar contra as candidaturas de políticos que consideravam liberais e "inimigos da família". Muitos dos "inimigos" sofriam uma espécie de "macartismo moral"14. A Maioria Moral e as diversas organizações da Direita Cristã também souberam se organizar para atuar no Congresso como grandes lobbies para aprovar projetos de seu interesse e impedir a tramitação e aprovação de leis "anticristãs".

LaHaye se tornou uma das mais importantes lideranças do processo de politização do discurso fundamentalista no final da década de 1970 e início da década de 1980. Foi um dos apoiadores de primeira hora dos posicionamentos de Jerry Falwell e, junto com ele, um dos fundadores da Maioria Moral. Antes da

\footnotetext{
${ }^{13}$ Entre a segunda metade da década de 1970 e a primeira metade da década de 1980, surgiram vários grupos de organização política defendendo as bandeiras da direita cristã. Entre eles: Focus on the family, Concerned Women for America, Family Research Council, Eagle Forum, Traditional Values Coalition, Citizens for Excellence in Education, e vários outros.

${ }^{14}$ Walter Mondale, vice-presidente durante o governo Carter e candidato democrata à presidência em 1984, por exemplo, foi "acusado" diversas vezes de ser homossexual.
} 
Religare, ISSN: 19826605, v.16, n.1, agosto de 2019, p.140-169.

Maioria Moral, LaHaye já havia fundado junto com sua esposa Beverly, em 1978, a organização Concerned Women for America (Mulheres Preocupadas para a América), que tinha por objetivo organizar as mulheres que combatiam as ideias feministas "anticristãs". Ele também apoiava uma série de outras associações que se definiam como pró-moral, pró-família e pró-vida.

No final da década de 1970, LaHaye, assim como grande parte da Direita Cristã, foi impactado pelos livros de Francis Schaeffer. Missionário presbiteriano com um trabalho voltado para a juventude com sede na Suíça, Schaeffer não era adepto de ideias dispensacionalistas (inclusive tinha pouco interesse por questões escatológicas) e permanecia muito fiel a um calvinismo mais ortodoxo. Ele não se encaixava muito bem no estereótipo do fundamentalista "padrão". Apesar disso, seus livros, especialmente How Should We Then Live? (Como viveremos?), de 1976, fizeram enorme sucesso e ajudaram a consolidar um discurso que seria popularizado por pastores midiáticos como Falwell e LaHaye: a sociedade norte-americana estaria em decadência, pois os valores cristãos nos quais havia sido fundada estariam sendo trocados por uma ideologia humanista, secularista e ateia. Um sinal claro disso teria sido a legalização da prática do aborto. Era necessário, para Schaeffer, que os verdadeiros cristãos tomassem consciência disso e se mobilizassem para essa batalha pela hegemonia cultural da nação.

Schaeffer forneceu à Maioria Moral um discurso articulado e um inimigo a ser combatido: o humanismo secular. As ideias e o "chamado para a batalha" de Schaeffer foram absorvidos pelas lideranças da Maioria Moral e ganharam ainda maior circulação na voz e nos textos de Jerry Falwell - como Listen, America! (Ouça, América!) de 1980 - e, também, num livro que se tornou uma das principais obras de referência para a Direita Cristã: The Battle for the Mind, de Tim LaHaye, cuja primeira edição foi publicada em agosto de 1980.

\section{A Batalha pela Mente}


Religare, ISSN: 19826605, v.16, n.1, agosto de 2019, p.140-169.

O livro foi dedicado a Schaeffer, o "renomado filósofo-profeta do século XX", que havia despertado LaHaye para o perigo do humanismo secular. LaHaye procurou demonstrar o que era o humanismo secular e como, em sua perspectiva, ele era uma "real ameaça" à herança cristã do país e, também, como havia dominado as estruturas de poder e da mídia norte-americanas. Em seguida, falava da apatia dos cristãos e dos cidadãos (não necessariamente cristãos) defensores dos valores morais e os conclamava a entrar nessa "batalha" contra o humanismo, inclusive apresentando as armas e as táticas que deveriam ser usadas. No texto, LaHaye falava de seus planos junto com Falwell para mobilizar as lideranças religiosas e organizar a Maioria Moral. Ele repete, em seus termos, o discurso da "maioria silenciosa" e da necessidade de líderes que viessem trazer esses norte-americanos conservadores para dentro da arena política: “um gigante adormecido está lá fora aguardando por alguém que os lidere, ansioso para fazer algo antes que seja tarde demais para impedir a destruição de nossa nação" (LAHAYE, 1980, p. 201) ${ }^{15}$.

O que seria o "humanismo secular" na perspectiva de LaHaye? Seria uma espécie de "espírito secularizador" que inspirava as transformações que estariam ocorrendo na cultura e na sociedade norte-americanas, afastando-as dos valores cristãos. O humanismo secular condensava em si uma série de "ameaças" e entraria no rol dos grandes mitos conspiratórios. Para LaHaye, o humanismo secular representava um enorme perigo para a sociedade norte-americana na medida em que, tendo se tornado a base intelectual das instituições governamentais, do meio acadêmico e da mídia norte-americana, tendia a "naturalizar" suas concepções de sociedade para que as pessoas as aceitassem "irrefletidamente". Em The Battle for the Mind, LaHaye afirmava que o humanismo secular teria como premissa básica a noção de uma total independência do homem em relação a Deus ou qualquer outra entidade

\footnotetext{
${ }^{15}$ No original: "a sleeping giant was out there, waiting for someone to lead them, anxious to do something before it was too late to stop the destruction of our nation".
} 
Religare, ISSN: 19826605, v.16, n.1, agosto de 2019, p.140-169. metafísica. Seus pilares seriam o ateísmo (sem Deus), a teoria da evolução (sem criação especial), amoralidade (relatividade dos princípios morais), autonomia (em relação às ordenanças e preceitos religiosos) e a necessidade de uma grande estrutura governamental (e socialista) para implantar suas ideias na sociedade "de cima para baixo".

Nos Estados Unidos, estaria havendo uma progressiva tomada do poder político e, também, das mentes, levando o país a trocar a "sabedoria de Deus" pela vã "sabedoria dos homens". A disseminação do humanismo secular estaria transformando uma sociedade que havia sido fundada tendo por princípios o cristianismo e a Bíblia em uma sociedade caótica e amoral. Os exemplos seriam vários. LaHaye criticava a teoria darwinista da evolução das espécies e dizia que o comportamento depravado dos norte-americanos seria fruto do "esvaziamento" da noção de que os homens teriam sido criados à imagem e semelhança de Deus. "Se você acredita que o homem é um animal, naturalmente você viverá como um"16. Para ele, essa concepção de ser humano abriu as portas para uma permissividade sexual sem precedentes e para a banalização do divórcio e do aborto, que estariam desestruturando as famílias norte-americanas. As famílias também estariam sendo alvo da educação sexual que era ensinada às crianças do jardim de infância até o high school (ensino médio), que acabava por estimulá-las a uma vida sexual precoce. Somava-se a tudo isso a aceitação da "homossexualidade como uma opção de estilo de vida; o acesso livre à pornografia, à maconha e ocasionalmente a drogas mais pesadas" (LAHAYE, 1980, p. 64) $)^{17}$.

O fato de os Estados Unidos terem se consolidado como a "terra da liberdade" só teria se tornado possível graças à "nossa forma de governo baseada na Bíblia e ao nosso incomparável sistema educacional também baseado nos

\footnotetext{
${ }^{16}$ No original: "If you believe that man is an animal, you will naturally except him to live like one".

17 No original: "homosexuality as an optional life-style; and free access to pornography, marijuana, and occasionally hard drugs".
} 
Religare, ISSN: 19826605, v.16, n.1, agosto de 2019, p.140-169.

ensinamentos bíblicos" (LAHAYE, 1980, p. 37) ${ }^{18}$. Na interpretação de LaHaye, tanto os Pais Peregrinos quanto os Pais Fundadores legaram ao povo norteamericano princípios de organização de governo e da vida em sociedade amplamente baseados em preceitos bíblicos. Por exemplo, o autor afirma que a noção de separação de poderes e a concepção dos checks and balances (freios e contrapesos) se tornaram necessários devido a uma crença compartilhada de que o homem é, por natureza, mau e pecador. Os humanistas, crentes na bondade inerente do ser humano, não teriam sido capazes de pensar em tais soluções para a organização das instituições nacionais. Os humanistas seculares teriam uma concepção equivocada sobre a necessidade de ampliação do Estado e "eles ignoram ou rejeitam a premissa de que o nível da liberdade sempre esteve em proporção inversa ao tamanho e poder do governo" (LAHAYE, 1980, p. 72) ${ }^{19}$. Seu objetivo último seria a criação de um governo socialista mundial único. As atitudes de antipatia ao capitalismo e, também, a forma como conduziam organizações que estariam sob seu controle - LaHaye cita a ONU, a UNESCO, o UNICEF, entre outras como propagadoras do humanismo secular - mostrava que eles eram devotos desse grande projeto internacional e tinham pouco ou nenhum espírito patriótico.

A consolidação do humanismo secular nos Estados Unidos teria se iniciado com o domínio que seus adeptos passaram a exercer sobre o sistema educacional público na década de 1950. Antes disso, segundo LaHaye, a educação tradicional fornecia o conhecimento necessário sobre ciência, mas também ensinava os princípios morais e abordava temas "realmente importantes" para os seres humanos (De onde vim?; Para onde vou?; Qual o sentido da vida? etc.). Bons teriam sido os tempos dos antigos livros didáticos, com suas "referências a Deus, obediência, moralidade e formação do caráter"

\footnotetext{
${ }^{18}$ No original: "our Bible-based form of government and our unique Bible-based educational system".

${ }^{19}$ No original: "they overlook or reject the premise that freedom has always been in inverse proportion to the size and power of government"
} 
Religare, ISSN: 19826605, v.16, n.1, agosto de 2019, p.140-169.

(LAHAYE, 1980, p. 41)20 que foram totalmente abolidos das escolas ao ser ridicularizados pelos educadores humanistas e liberais. A educação pública "préhumanista" partia da concepção de um Deus Criador, do qual seríamos servos neste mundo, e da moral judaico-cristã (baseada no Decálogo). Mas tudo isso teria ido, progressivamente, por "água abaixo. Deus teria sido, aos poucos, "expulso" das escolas públicas norte-americanas. O grande "ardil" humanista seria dominar a educação pública para conquistar as mentes dos jovens e impor a hegemonia humanista sobre as gerações seguintes.

No entendimento de LaHaye, o humanismo secular impunha seus preceitos sobre o sistema educacional norte-americano a partir do controle que exercia nas universidades. Os principais idealizadores do "projeto" do humanismo secular seriam os professores universitários - responsáveis pela formação dos educadores que, segundo LaHaye, reproduziriam o que haviam aprendido para seus alunos nas escolas públicas. Entre os motivos de "escândalo" dos fundamentalistas estavam: o ensino da teoria da evolução das espécies (seu já "velho inimigo"); as aulas sobre educação sexual; referências consideradas como negativas a Deus e ao cristianismo; ideias com tendências à esquerda sobre política e economia, defendidas por alguns professores em sala de aula etc. Uma questão que havia se tornado uma "bandeira de luta" pessoal de LaHaye na Califórnia era a presença de professores homossexuais nas escolas públicas ${ }^{21}$. Eles seriam, no entendimento do autor, uma péssima influência para as crianças e fariam parecer normal - e mesmo incentivariam - um "estilo de vida" que seria condenado pelo ensino das Sagradas Escrituras. "Sempre que se

\footnotetext{
${ }^{20}$ No original: "references to God, obedience, morality, and character building".

${ }^{21}$ LaHaye lançou, em 1978, o livro The Unhappy Gays: What Everyone Should Know About Homosexuality no qual afirmava que o crescimento e a aceitação da homossexualidade seria uma das razões da degeneração da cultura norte-americana. Também participou de uma série de mobilizações e protestos contra a expansão de direitos dos homossexuais. Em The Battle for the Mind, ele diz em certo momento que "they are demanding homosexual rights in everything: housing, employment, marriage, and even adoption of children. In other words, an employer has no right to employ only heterosexuals. Humanists demand complete rights for those who choose the homosexual life-style".
} 
Religare, ISSN: 19826605, v.16, n.1, agosto de 2019, p.140-169.

permitir que os professores homossexuais exaltem a homossexualidade como um estilo de vida opcional para crianças pré-púberes, a população homossexual dobrará em dez anos" (LAHAYE, 1980, p. 213)22 - logicamente, LaHaye não apresentava nenhum dado que fornecesse algum subsídio para essa afirmativa.

Tudo isso seria agravado, ainda mais, com a regulamentação de leis sobre "direitos das crianças" que, no entendimento dos fundamentalistas, seria uma forma utilizada pelos humanistas para limitar o direito dos pais de disciplinar seus filhos. E todo esse aparato de "doutrinação humanista" estaria sendo bancado com o dinheiro dos contribuintes norte-americanos, mesmo o daqueles pais que não concordavam com o que acontecia nas salas de aula. De acordo com LaHaye (1980, p. 130-131), para propagarem os valores de sua "religião"23, os humanistas seculares:

recebem 140 bilhões de dólares anualmente para operar sua vasta rede de igrejas, chamadas escolas, faculdades e universidades. Por que eles precisariam coletar doações para apoiar a propagação de sua religião quando através de nossos impostos, nós pagamos por seus serviços? Os pais são obrigados a enviar seus filhos impressionáveis para escolas onde, em nome da liberdade acadêmica, só a religião do humanismo pode ser ensinada ${ }^{24}$.

Dessa forma, se os movimentos sociais da década de 1960, setores da mídia e mesmo de Hollywood seriam importantes meios de propagação dos ideais do humanismo secular, LaHaye afirmava que toda essa aceitação de princípios

\footnotetext{
${ }^{22}$ No original: "Whenever homossexual teachers are allowed to exalt homosexuality as an optional life-style to prepubertal children, the homossexual population will double in ten years". ${ }^{23}$ Em vários momentos, LaHaye disse que o humanismo secular seria uma espécie de religião. Por exemplo, a crença na teoria da evolução seria uma questão de fé e não de ciência. $O$ humanismo secular teria, inclusive, sua própria "teologia": "Humanism has constructed a welldefined theology: Disbelief in God; Belief in evolution; Rejection of absolute morals; Deification of man as supreme; Belief in the innate goodness of men to govern the world equitably" (LAHAYE, 1980, p. 130).

${ }^{24}$ No original: "receive 140 billion dollars annually to operate their vast network of churches, called schools, colleges, and universities. Why should they collect donations to support the propagation of their religion when through our taxes, we pay for their services? Parents are compelled to send their impressionable children to schools where, in the name of academic freedom, only the religion of humanism can be taught".
} 
Religare, ISSN: 19826605, v.16, n.1, agosto de 2019, p.140-169.

"antibíblicos" na sociedade norte-americana só tinha se tornado viável com o domínio do aparelho estatal pelos "militantes humanistas". Para LaHaye, essa também era a razão do enfraquecimento norte-americano como grande potência mundial e liderança do "mundo livre". Após a Segunda Guerra Mundial, os líderes políticos dos Estados Unidos estariam mais interessados no "socialismo mundial do que nos Estados Unidos" (LAHAYE, 1980, p. 77) ${ }^{25}$. O poder comunista se expandira pelo mundo afora e os insucessos na Coreia e no Vietnã seriam uma demonstração do enfraquecimento da "terra da liberdade". A ameaça do "comunismo interno" era cada vez maior. Os fundamentalistas faziam coro com o discurso de que "o comunismo ameaçava a religião dos americanos, ameaçava as liberdades básicas da tradição americana [...]" (TOTA, 2014, p. 208). Os humanistas seculares seriam representantes de uma pequena parcela da população norte-americana, mas haviam conseguido impor sua hegemonia cultural ao país através do poder político. Presidentes, juízes da Suprema Corte, congressistas etc. estariam, em sua grande maioria, a serviço do humanismo secular.

The Battle for the Mind apresentava essa conjuntura sombria, mas, por outro lado, conclamava os cristãos a agirem efetivamente e a "sujarem" suas mãos no profano campo da política. A única força que poderia ameaçar o avanço do humanismo secular seria uma igreja militante e engajada. Não se poderia contar com as igrejas liberais que seriam só mais um braço do humanismo secular, uma expressão com elementos religiosos de seus valores "anticristãos". A verdadeira força era a do que ele chamava de cidadãos pro-moral, crentes nas verdades bíblicas e no poder do Espírito Santo para derrotar as forças satânicas. "Somente uma organização nos Estados Unidos pode parar a completa 'humanização' de nossa nação: a igreja de Jesus Cristo. Infelizmente, a igreja parece apática em sua

\footnotetext{
${ }^{25}$ No original: "more interested in world socialism than in America".
} 
Religare, ISSN: 19826605, v.16, n.1, agosto de 2019, p.140-169.

resposta ao humanismo" (LAHAYE, 1980, p. 125)26. Seria necessário conscientizar os verdadeiros crentes a respeito da necessidade de entrarem na "guerra". LaHaye (1980, p. 79) acreditava que, se a Igreja tomasse consciência da ameaça que significava a vitória dos humanistas na "batalha pelas mentes", ela “despertaria os outros milhões de americanos pro-moral, e juntos, através de seus votos, retirariam os humanistas amorais de seus gabinetes e os substituiriam por líderes tradicionais e pro-moral" 27.

Como dissemos, a ideia de uma "Maioria Moral" vinha da percepção dos fundamentalistas de que, apesar de formarem um grupo de ação política relativamente reduzido, suas ideias representavam o sentimento e as convicções da maioria dos norte-americanos. Essa grande maioria de cidadãos pro-moral estaria se omitindo há tempo demais sobre a vida política dos Estados Unidos e acabou por dar espaço para que uma pequena, porém influente e extremamente articulada, minoria de humanistas seculares ocupasse os postos de poder da nação e utilizasse a estrutura e a influência do aparelho estatal para disseminar sua satânica ideologia. Apenas a "Igreja de Cristo" seria capaz de "virar o jogo", mas ela não estaria sozinha. A Maioria Moral, apesar de coordenada por fundamentalistas que tinham fortes tendências exclusivistas e sectaristas em questões de fé, se abriu, no campo político, para alianças com outros grupos. Passaram a empunhar algumas bandeiras juntos com pessoas cujas crenças consideravam falsas - como mórmons, judeus e católicos conservadores -, mas que compartilhavam, com os fundamentalistas, de certos valores morais. A importância da defesa da "América" contra o avanço do humanismo secular sobrepunha-se às discussões sobre a "teologia correta" e mesmo sobre a exclusividade do cristianismo. LaHaye (1980, p. 187) dizia que "por trinta anos,

\footnotetext{
${ }^{26}$ No original: "Only one organization in America can stop the complete 'humanization' of our nation: the church of Jesus Christ. Unfortunately, the church seems apathetic in its response to humanism".

${ }^{27}$ No original: "will awaken the other millions of pro-moral Americans, and together they will vote their amoral humanist overlords out of office and replace them with traditional, pro-moral leaders".
} 
Religare, ISSN: 19826605, v.16, n.1, agosto de 2019, p.140-169.

tenho sido um fundamentalista bíblico com fortes convicções doutrinárias. [...] A batalha contra o humanismo, no entanto, não é teológica; é moral"28.

Os "heréticos" católicos e mórmons tornaram-se importantes aliados dos fundamentalistas nas cruzadas contra os ataques aos "valores da família", como na questão do aborto, do combate à pornografia e à educação sexual "laica" nas escolas públicas. Nessa grande coalizão conservadora que se formava no final da década de 1970, compartilhava-se a ideia de que "os radicais da década de 1960 haviam se tornado professores e imposto sua visão de mundo 'ideológica' ao resto da nação" (ÁVILA, 2015, p. 42). Outro grupo de aliados eram os neocons (neoconservadores). Apesar de seus principais articuladores serem judeus e muitos sem maior interesse em questões propriamente religiosas, os neocons tinham na nova direita religiosa um importante aliado na difusão de suas ideias sobre economia e suas críticas ao crescimento do tamanho do Estado e às políticas de welfare nos Estados Unidos. De acordo com Schlesinger Jr. (1992, p. 45), as ondas de conservadorismo religioso e o foco na ênfase privada em questões econômicas andariam lado a lado. No ciclo de ênfase no privado, que ganhava corpo nos Estados Unidos no final da década de 1970, reabasteciam-se “o eu, a família e a economia privada, renovando as defesas contra uma sociedade massificada e um Estado agressivo".

Por todo o país, os pregadores nos púlpitos dividiam suas mensagens entre a busca pelas almas e o combate ao comunismo, à legalização do aborto, à expansão dos direitos dos homossexuais e à "frouxidão" dos governos. "Um novo espírito de ativismo moral surgiu entre os pastores de nossa nação; por meio deles, esse espírito se difundirá entre os membros das igrejas e influenciará os milhões de outros cidadãos pro-moral que reivindicarão: 'Este é o nosso país'” (LAHAYE, 1980, p. 199) ${ }^{29}$. É importante relembrar que, quando essa mobilização

\footnotetext{
${ }^{28}$ No original: "for thirty years, I have been a biblical fundamentalist with strong doctrinal convictions. [...] The battle against humanism, however, is not theological; it is moral".

${ }^{29}$ No original: "A new spirit of moral activism was born among the ministers of our nation; through them, it will permeate church members and influence the millions of other pro-moral citizens who demand, 'This is our country'"
} 
Religare, ISSN: 19826605, v.16, n.1, agosto de 2019, p.140-169.

política ganhou corpo, havia toda uma estrutura para que suas ideias, campanhas e propostas fossem disseminadas. Essas organizações fundamentalistas - "uma impressionante infraestrutura nacional de redes pastorais, organizações paraeclesiásticas e super-igrejas, escolas e faculdades, editoras de livros e revistas, rádios, emissoras e programas de TV e operações de mala direta" (RUTHVEN, 2007, p. 16) 30 $^{30}$ pensadas inicialmente como veículos propagadores da "mensagem da salvação" e de refúgio para os "verdadeiros fiéis" frente à pecaminosidade que marcava a sociedade secular, tornaram-se importantes ferramentas na divulgação do novo "Evangelho político".

O último capítulo de The Battle for the Mind começa com uma improvável epígrafe de John F. Kennedy (um dos presidentes mais rejeitados pelos fundamentalistas): “Do not ask what America can do for you; ask what you can do for America" (Não pergunte o que os Estados Unidos podem fazer por você; pergunte o que você pode fazer pelos Estados Unidos". ${ }^{31}$ Intitulado "What you can do" (O que podemos fazer?), esse capítulo é uma espécie de "cartilha" sobre como o cidadão pro-moral engajado poderia e deveria agir na arena política. Inicialmente, ele reafirma três questões espirituais que sempre fizeram parte da retórica fundamentalista: oração pelas autoridades; continuar pregando e compartilhando as "verdades do Evangelho" (quanto mais conversos, melhor a sociedade); e ter ações condizentes com uma genuína fé cristã. Mas, após essas exortações de fundo espiritual, LaHaye elenca uma série de ações pragmáticas que deveriam ser tomadas para "resgatar" a "América para Jesus": promoção de uma campanha nacional para registro de eleitores; ${ }^{32}$ prestar auxílio voluntário às

\footnotetext{
30 No original: "an impressive national infrastructure of pastoral networks, parachurch organizations and superchurches, schools and colleges, book and magazine publishing industries, radio, television and direct-mail operations".

${ }^{31}$ Há uma alteração, se acidental ou deliberada não sabemos, na citação de LaHaye em relação ao discurso original de Kennedy de 20 de janeiro de 1961, no qual ele disse: "And so, my fellow Americans: ask not what your country can do for you - ask what you can do for your country". ${ }^{32}$ Isso seria uma necessidade para dar maior peso eleitoral aos grupos fundamentalistas. "We have already pointed out that between 8 and 10 million Christians are not even registered to vote" (LAHAYE, 1980, p. 229). A fonte de tais números não foi mencionada.
} 
Religare, ISSN: 19826605, v.16, n.1, agosto de 2019, p.140-169.

campanhas de candidatos comprometidos com valores morais; engajar-se em "desmascarar" candidatos defensores de projetos e concepções humanistas; informar-se e buscar informar os amigos e vizinhos sobre as propostas e a conduta moral dos candidatos; caso se sinta preparado, o cristão deve considerar concorrer a algum cargo público; e, por fim, engajar-se e ajudar no sustento de organizações pro-moral.

\section{Enquanto Jesus não volta...}

E a questão escatológica, o tema que tornou LaHaye conhecido mundialmente? Embora The Battle for the Mind não seja um livro cujo foco central fosse a discussão de questões relativas ao fim dos tempos - como The Beginning of the End ou No Fear of the Storm, obras de LaHaye sobre escatologia lançadas na década de 1970 - LaHaye não deixou de tocar no tema ao longo do livro e, inclusive, dedicou um capítulo inteiro à discussão das relações entre suas convicções sobre escatologia e o chamado ao engajamento político dos cristãos. Para ele, pré-milenarismo não seria sinônimo de apatia. LaHaye criticava aqueles que, por verem como inevitável o avanço do mal nos últimos dias, se abstinham da participação nas questões políticas: "Isso não é bíblico! Somos ordenados a resistir ao diabo e vestir toda a armadura de Deus, para que possamos resistir no dia mal" (LAHAYE, 1980, p. 217) 33 .

Por que agir politicamente se o "mundo jaz no Maligno", a volta de Cristo é iminente e o verdadeiro reinado de paz e justiça só haveria de ocorrer com o próprio Jesus reinando em Jerusalém no Milênio? LaHaye estava plenamente ciente dessas aparentes contradições entre a sua escola escatológica e o que seu livro de 1980 advogava. Ele relembrava as palavras que ouvia do pastor de sua igreja na década de 1940, que o influenciaram por muito tempo: “A política é um negócio sujo. Ao invés de nos envolvermos em política, nós, cristãos, devemos

\footnotetext{
${ }^{33}$ No original: "This is unscriptural! We are commanded to resist the devil and to put on the whole armor of God that we may be able to withstand in the evil Day".
} 
Religare, ISSN: 19826605, v.16, n.1, agosto de 2019, p.140-169.

nos apegar à pregação do Evangelho e deixar que as boas mentes cívicas administrem o país" (LAHAYE, 1980, p. 190)34. O desinteresse por questões políticas e, consequentemente, pelo futuro das instituições norte-americanas era uma "acusação" constantemente feita aos pré-milenaristas por seus adversários. LaHaye dizia que, enquanto os cristãos fundamentalistas se dedicavam a construir igrejas, seminários, escolas etc. um pequeno grupo de humanistas seculares ocupou as esferas de poder nos Estados Unidos. O papel espiritual e a função missionária das igrejas seriam as prioridades dos fiéis no mundo, mas "nós, cristãos, abandonamos quase totalmente o segundo campo mais importante para influenciar as pessoas hoje - o governo. Estamos satisfatoriamente representados no primeiro [missão espiritual], através das atividades da igreja, mas negligenciamos o segundo, colocando em perigo nossa nação!" (LAHAYE, 1980, p. 186) 35. A prova dessa constatação seria o fato de que estaria havendo um crescimento das igrejas fundamentalistas e do número dos que se confessavam born again christians no país, ao mesmo tempo em que os valores morais estariam em deterioração. Em relação à nação como um todo, a Igreja de Jesus estaria sendo como "sal que não salga" e "luz que não ilumina". Entretanto, no seu primeiro best-seller sobre escatologia, The Beginning of the End (O começo do fim), lançado em 197236, LaHaye parecia "conivente" com essa situação ao relatar todo o colapso moral por que passava a sociedade norteamericana e, ao final do livro, conclamar as pessoas a se voltarem para Jesus, sem tocar em momento algum na necessidade de qualquer engajamento em relação a questões políticas. Em The Battle for the Mind, ele fez seu mea culpa: "Não estou

\footnotetext{
${ }^{34}$ No original: "Polítics is a dirty business. Rather than getting involved in politics, we Christians should stick to preaching the gospel and let the nice civic-minded people run the country".

${ }^{35}$ No original: "we Christians have almost totally abandoned the second-most-important field for influencing people today - government. We are satisfactorily represented in the first through the activities of the church, but we have neglected the second at our nation's peril!".

${ }^{36}$ O livro foi lançado em 1972. Para este trabalho usamos a edição de 1974, oitava tiragem da obra.
} 
Religare, ISSN: 19826605, v.16, n.1, agosto de 2019, p.140-169.

condenando os meus colegas pastores. Eu certamente sei de onde eles estão vindo, porque eu estava lá há apenas cinco anos" (LAHAYE, 1980, p. 191) ${ }^{37}$.

Se essa postura que LaHaye agora renegava seria coerente com o prémilenarismo e a crença na iminência da volta de Jesus, em 1980 ele apresentava argumentos aparentemente paradoxais: se, de um lado, não teria voltado atrás em sua crença de que a sua geração seria aquela que veria a volta de Jesus, por outro lado, o livro inteiro apontava para a necessidade de recuperar os valores morais do país para construir um futuro melhor para as futuras gerações. Se o futuro ainda se apresentava com um ar sombrio devido à apatia que ainda prevalecia entre a "maioria moral" 38 , as próximas décadas poderiam se tornar uma nova "era de ouro" na história dos Estados Unidos: "Se, no entanto, líderes pro-moral de todas as convicções religiosas estiverem dispostos a permanecer juntos como companheiros americanos preocupados com a preservação da família e decência moral, ainda podemos ganhar esta batalha implacável por nossas mentes e as de nossos filhos" (LAHAYE, 1980, p. 188) ${ }^{39}$. Recupera-se aqui uma crença arraigada entre vários norte-americanos desde o período dos grandes avivamentos dos séculos XVIII e XIX: santidade moral e fervor religioso seriam pré-condições para o "sucesso" dos Estados Unidos. LaHaye acreditava que o país estaria sendo abençoado com um novo Grande Avivamento, que teria implicações práticas na vida política do país, com a queda dos políticos humanistas e a sua substituição por outros, comprometidos com uma agenda promoral. "Eu creio que o Senhor salvará os Estados Unidos se a igreja liderar agressivamente a maioria pro-moral no sentido de dar um fim nesse deslizamento

\footnotetext{
${ }^{37}$ No original: "I am not condemning my minister colleagues in the slightest. I certainly know where they are coming from, for I was there just five years ago".

38 Nesse momento, não falamos da organização Moral Majority, mas sim do que ela afirmava representar: os cidadãos norte-americanos para os quais as questões morais tinham significado fundamental para o futuro do país. Essas pessoas, no entendimento de Falwell e LaHaye, seriam a maioria dos eleitores norte-americanos.

${ }^{39}$ No original: "If, however, pro-moral leaders of all religious persuasions are willing to stand together as fellow Americans concerned with preservation of the family and moral decency, we can still win this relentless battle for our minds and those of our children".
} 
Religare, ISSN: 19826605, v.16, n.1, agosto de 2019, p.140-169.

de tobogã rumo à depravação e devolver nossa nação à sanidade moral" (LAHAYE, 1980, p. 190) ${ }^{40}$. A responsabilidade dos cristãos norte-americanos não seria apenas com a questão espiritual e com a salvação das almas. Também era necessário lutar contra a disseminação de valores anticristãos nos Estados Unidos: "Eu sou um cristão comprometido, e eu sou um americano comprometido. O humanismo é viciosamente oposto a ambos" (LAHAYE, 1980, p. 138$)^{41}$.

Mas, no entendimento de LaHaye, não seria a "decadência moral" um sinal previsto na Bíblia de que estaríamos vivendo no fim dos tempos? Ela não seria uma pré-condição para o começo da Tribulação, o estabelecimento do reino do Anticristo na Terra e a volta de Jesus? Sim, de acordo com o autor os homens dos últimos dias seriam "depravados". Mas não necessariamente as pessoas de todos os países estariam em apostasia no período que antecederia o início da Tribulação: "Não é necessário que tal situação seja uma realidade em todos os países do mundo à medida que nos preparamos para a vinda de Cristo" (LAHAYE, 1980, p. 218) ${ }^{42}$. Como pré-tribulacionista convicto, LaHaye acreditava que os sete anos da "última semana de Daniel" só teriam início após o Arrebatamento dos crentes. Enquanto esse Arrebatamento não ocorresse, a Igreja ainda estaria na Terra e seria chamada a agir "no" mundo. E o país onde os valores defendidos pela "verdadeira igreja" de Cristo ainda poderiam fazer diferença eram os Estados Unidos. Em The Battle for the Mind, LaHaye mostra-se um verdadeiro "crente" na noção da "América como destino", na "nação redentora" e no excepcionalismo norte-americano. Analisando os conflitos que marcaram o século $\mathrm{XX}$, como as duas guerras mundiais e o avanço do comunismo, LaHaye dizia que o mundo não havia entrado em total colapso

\footnotetext{
${ }^{40}$ No original: "I believe He will save America, if the church will aggressively lead the pro-moral majority to stop this toboggan slide to depravity and return our nation to moral sanity".

${ }^{41}$ No original: "I am a commited Christian, and I am a commited American. Humanism is viciously opposed to both".

${ }^{42}$ No original: "Such a condition does not have to exist in every country in the world as we prepare for the coming of Christ".
} 
Religare, ISSN: 19826605, v.16, n.1, agosto de 2019, p.140-169.

devido às fortes raízes cristãs que ainda estavam presentes nos Estados Unidos. Em outro momento, ele afirmava que, mesmo "com o risco de ser acusado de orgulho nacionalista, gostaria de assinalar que, se não fosse a influência cristã nos Estados Unidos, o nosso mundo contemporâneo teria perdido completamente a batalha pela mente e viveria, sem dúvida, num Estado mundial, totalitário e humanista" (LAHAYE, 1980, p. 35) ${ }^{43}$. Portanto, enquanto Cristo não vier em segredo para levar os seus "santos" consigo, os Estados Unidos poderiam - e deveriam - ser um luzeiro para o mundo.

\section{Considerações finais}

O sociólogo James Davidson Hunter (1991), analisando a história norteamericana a partir das últimas décadas do século XIX, percebeu que as principais tensões internas nos Estados Unidos até a primeira metade do século XX giravam em torno de confrontos entre minorias étnicas/religiosas e a majoritária "América WASP". Setores conservadores do protestantismo consideravam que as principais "ameaças" à civilização protestante no Novo Mundo seriam a expansão do catolicismo e a maior presença de judeus. Entretanto, Hunter diz que, ao longo do século XX, o conflito étnico/civilizacional foi, progressivamente, perdendo sua proeminência. As polêmicas que ganharam maior espaço na sociedade norte-americana durante a partir da década de 1960 - como a legalização do aborto, descriminalização das drogas, limites da liberdade de expressão, ampliação dos direitos dos homossexuais etc. - deveriam, na ótica de Hunter, ser analisadas a partir de um conflito mais profundo que se dá em torno de discordâncias sobre o que é "justo”, “bom”, "bem comum”, enfim, sobre quais princípios devem ordenar a sociedade. Começaram a perder espaço, então, as divisões teológicas, étnicas e raciais e ganharam proeminência desacordos sobre

\footnotetext{
${ }^{43}$ No original: "At the risk of being accused of nationalistic pride, I would point out that, had it not been for the Christian influence in America, our contemporary world would have completely lost the battle for the mind and would doubtless live in a totalitarian, one-world, humanistic state".
} 
Religare, ISSN: 19826605, v.16, n.1, agosto de 2019, p.140-169.

visões de mundo e sobre o significado dos Estados Unidos como nação. As Culture Wars, portanto, são "discussões sobre o que é fundamentalmente certo e errado a respeito do mundo em que vivemos - sobre o que é, no fim das contas, bom e o que é totalmente intolerável em nossas comunidades" ${ }^{44}$. Sobre a questão da identidade nacional, tratava-se de decidir "quem nós, enquanto uma nação, temos sido, entender o que somos agora e definir o que devemos aspirar nos tornar no futuro" 45 (HUNTER, 1991, p. 31; 108).

Hunter buscou definir mais claramente essa divisão. Essa "cisão cultural" da sociedade norte-americana se daria entre dois polos que ele denomina como impulse toward orthodoxy e impulse toward progressivism, ou poderíamos dizer, entre uma perspectiva mais conservadora e voltada para valores tradicionais (entre eles a religião) e outra de caráter mais progressista e secularizada. Os "tradicionalistas" orientariam suas ações a partir de valores considerados atemporais - verdades eternas e imutáveis - e, no mais das vezes, de origem transcendente. Os "progressivistas", por outro lado, partiriam de uma percepção moderna de que os valores deveriam se adaptar ao "espírito do tempo". George Marsden (2001, p. 248-249) tem uma perspectiva semelhante sobre essa divisão na sociedade norte-americana. Entretanto, ele utilizou o antigo binômio conservadores/liberais para identificar os polos dos conflitos. No lado liberal, estariam os indivíduos e grupos comprometidos com a defesa da pluralidade, da tolerância com a diversidade de estilos de vida, expressões de sexualidade etc. Os conservadores, por sua vez, focavam suas crenças em "verdades eternas", baseadas em ensinamentos da religiosidade judaico-cristã, a respeito de família, ordem, disciplina e moral. Também se caracterizavam por um forte senso de patriotismo, defesa de um aparato militar poderoso e por um intenso "espírito" anticomunista (ou anti qualquer outra coisa que pudesse a ele ser vinculado).

\footnotetext{
${ }^{44}$ No original: "discussions about what is fundamentally right and wrong about the world we live in - about what is ultimately good and what is finally intolerable in our communities". ${ }^{45}$ No original: "who we are as a nation have been, coming to grips with who we are now, and defining what we should aspire to become in the future".
} 
Religare, ISSN: 19826605, v.16, n.1, agosto de 2019, p.140-169.

The Battle for the Mind, nos termos de Hunter, pode ser visto como um manifesto declarado de chamamento dos cristãos para uma culture war (obviamente do lado conservador) ou, numa expressão mais espiritualizada, para uma luta pela salvação da "alma da nação". Os humanistas estariam profanando a "santidade" dos Estados Unidos, não respeitando nem a herança cultural dos Pais Peregrinos. O livro teve importância fundamental para a Direita Cristã norte-americana: identificou o "inimigo" (o humanismo secular), reforçou o discurso da Maioria Moral, legitimou o engajamento político dos cristãos mesmo os que aguardavam o retorno imediato de Cristo - e indicou atitudes práticas de mobilização e ação política visando a "re-cristianização" da política e da cultura norte-americana.

Embalados pela força da “onda conservadora" do final da década de 1970, LaHaye e as outras lideranças da Direita Cristã estavam cada vez mais convictos de que vários de seus valores eram compartilhados pela maioria da população norte-americana, a "maioria silenciosa". A ênfase no discurso de que eram um grupo minoritário e perseguido pelo mundo que "jaz no Maligno" - e que se fiava apenas na volta de Jesus para que as "coisas" pudessem melhorar - perdeu espaço para uma expectativa de construção do reino de Deus em terras norteamericanas. De acordo com Williams (2010, p. 160), “no final da década de 1970, os evangélicos desfrutavam de um grau de riqueza e de prestígio social maior do que em qualquer outro momento do século $X X^{\prime \prime 46}$.

A Direita Cristã entrou na década de 1980 extremamente fortalecida politicamente e, podemos dizer, ocupando um importante lugar no mainstream cultural norte-americano. Um ambiente muito diferente do início da década de 1970. E o otimismo se tornou ainda maior com a eleição de Ronald Reagan. Apesar de nunca ter sido um cristão muito fervoroso ${ }^{47}$, Reagan percebeu a imensa

\footnotetext{
${ }^{46}$ No original: "evangelicals enjoyed a higher degree of wealth and social prestige in the late 1970s than they had at any other point in the twentieth century".

47 De acordo com Elliot (1988, p. 125), "os jornalistas gostam muito de destacar o fato de que Ronald Reagan não costuma[va] frequentar a igreja e que nunca expressou crenças religiosas
} 
Religare, ISSN: 19826605, v.16, n.1, agosto de 2019, p.140-169.

força da Direita Cristã e abraçou as suas bandeiras ${ }^{48}$, construindo um discurso que agradava as lideranças fundamentalistas. Tim LaHaye, que já possuía uma boa relação com Reagan desde seus períodos como governador da Califórnia, tornou-se uma das lideranças religiosas mais influentes junto ao governo norteamericano durante os anos em que o republicano esteve na Presidência. Inclusive, de acordo com Finguerut (2009, p. 127-128), LaHaye foi um dos coordenadores da campanha à reeleição de Reagan em 1984. Organizados como uma grande força dentro do Partido Republicano ${ }^{49}$, os fundamentalistas começaram a sentir o "gostinho" do poder. Sentiam-se, no início dos anos 1980, como peças importantes do tabuleiro político norte-americano, com fácil acesso ao presidente e capazes de influenciar os resultados das eleições e a escolha de juízes conservadores para a Suprema Corte.

Refazendo nossa "ponte" inicial com a participação dos evangélicos na política brasileira recente, podemos perceber que esse ápice de prestígio do conservadorismo religioso nos Estados Unidos em meados da década de 1980, coincide com o início da mobilização das igrejas brasileiras (especialmente as pentecostais e neopentecostais) para eleger seus representantes nas casas legislativas pelo Brasil afora. Podemos falar em uma “importação dos discursos"? No início de 1986, o livro “Irmão vota em irmão" de Josué Sylvestre ecoava entre os membros das Assembleias de Deus um tipo de discurso com argumentos muito próximos àqueles presentes em The Battle for the Mind:

particularmente fortes até o despontar da Maioria Moral, considerada por muitos como um dos responsáveis por sua eleição em 1980".

${ }^{48}$ De acordo com Marsden (2001), uma pesquisa Gallup de 1982 dizia que cerca de 25\% do eleitorado norte-americano se identificava com os valores e bandeiras da Maioria Moral. A aproximação entre Reagan e o discurso da Direita Cristã já vinha do período em que o candidato republicano era governador da Califórnia: "he knew how to appeal to evangelicals' sense of moral propriety. As governor of California, he had signed tough antiobscenity legislation, as well as a measure allowing parents to remove their children from sex education classes, and he had prided himself on his ability to stand up to left-wing protestors on college campuses"' (WILLIAMS, 2010, p. 123).

${ }_{49}$ Em 1992, “47\% dos delegados republicanos à convenção nacional do partido eram cristãos renascidos" (FINGUERUT, 2009, p. 131). 
Religare, ISSN: 19826605, v.16, n.1, agosto de 2019, p.140-169.

Será agora, em 1986 [eleição na qual seriam eleitos os deputados constituintes], ou nunca mais! Ou sacudimos esse opróbrio dos nossos ombros, livrando-nos dessa acomodação, desse desinteresse, dessa falta de coordenação, dessa falta de inteligência, dessa falta de amor, e elegemos parlamentares e administradores evangélicos em todas as eleições que surgirem de agora em diante, ou veremos o nosso país, cada vez mais, sendo arrastado para o lodaçal da corrupção e da má administração. (SYLVESTRE, 1986, p. 29).

A oração e o testemunho cristão deveriam agora ser acompanhados da ação: "Este é o binômio infalível: Oração e Ação. Não adianta apenas orar pelo Brasil. É preciso lutar por ele com as armas de que dispomos: pacíficas, legais, honradas - as nossas atitudes e, sobretudo o nosso voto." (SYLVESTRE, 1986, p. 30). O resultado de tal mobilização refletiu-se nas urnas naquela época e ainda repercute até hoje na política brasileira. Nesse sentido, esperamos que este texto tenha lançado luz não apenas sobre um importante período da história das relações entre fundamentalismo religioso e política nos Estados Unidos, mas também levantado algumas questões a serem trabalhadas por pesquisadores das práticas e discursos políticos do conservadorismo religioso brasileiro contemporâneo.

\section{Referências}

ALVES JR., Alexandre Guilherme da Cruz. A Direita Cristã e o florescer econômico do sunbelt nos anos 1980. Revista Cantareira, n. 18, p. 67-81, 2013. Disponível em: http://periodicos.uff.br/cantareira/article/view/27736/16145. Acesso em: 15 ago. 2017.

ÁVILA, Arthur Lima de. A quem pertence o passado norte-americano? A controvérsia sobre os National History Standards nos Estados Unidos (19941996). Anos 90, Porto Alegre, v. 22, n. 41, p. 29-53, 2015. Disponível em: https://seer.ufrgs.br/anos90/article/view/51290/34947. Acesso em: 15 ago. 2017. 
Religare, ISSN: 19826605, v.16, n.1, agosto de 2019, p.140-169.

ELLIOT, Emory. Religião, identidade e expressão na cultura americana: motivo e significado. In: SACHS, Viola [et al.]. Brasil $\mathcal{E}$ EUA: religião e identidade nacional. Rio de Janeiro: Graal, 1988. p. 113-139.

FALWELL, Jerry. Listen, America! Nova York: Doubleday \& Company, 1980.

FINGUERUT, Ariel. Formação, crescimento e apogeu da Direita Cristã nos Estados Unidos. In: SILVA, Carlos Eduardo Lins da (Org.). Uma nação com alma de igreja: religiosidade e políticas públicas nos EUA. São Paulo: Paz e Terra, 2009. p. 113-155.

HUNTER, James Davison. Culture wars: the struggle to define America. New York: Basicbooks, 1991.

LAHAYE, Tim. The beginning of the end. Wheaton: Tyndale House Publishers, 1974.

. The battle for the mind. New Jersey: Fleming H. Revell, 1980.

MARSDEN, George M. Religion and American culture. 2. ed. Harcourt College Publishers, 2001.

MARDSEN, George M. Fundamentalism and American Culture. 2. ed. New York: Oxford University Press, 2006.

MORONE, James A. Hellfire Nation: the politics of sin in American history. New Haven \& London: Yale University Press, 2003.

RUTHVEN, Malise. Fundamentalism: a very short introduction. Oxford: Oxford University Press, 2007.

SCHLESINGER JR., Arthur M. Os ciclos da história americana. Rio de Janeiro: Civilização Brasileira, 1992.

SYLVESTRE, Josué. Irmão vota em irmão: os evangélicos, a constituinte e a Bíblia. Brasília: Pergaminho, 1986.

TOTA, Antônio Pedro. Os americanos. São Paulo: Companhia das Letras, 2014.

URBAN, Hugh B. America, left behind: Bush, the neoconservatives, and evangelical Christian fiction. Omaha, Journal of Religion $\mathcal{E}$ Society, v. 8, p. 1-15, $2006 . \quad$ Disponível em: https://dspace2.creighton.edu/xmlui/bitstream/handle/10504/64544/20062.pdf? sequence=1. Acesso em: 15 ago. 2017.

WEBER, Timothy. On the Road to Armageddon: How Evangelicals Became Israel's Best Friend. Baker Academic, 2004.

WILLIAMS, Daniel K. God's own party: the making of the Christian Right. New York: Oxford University Press, 2010.

Recebido em 15-09-2018.

Aprovado em 15-10-2019. 